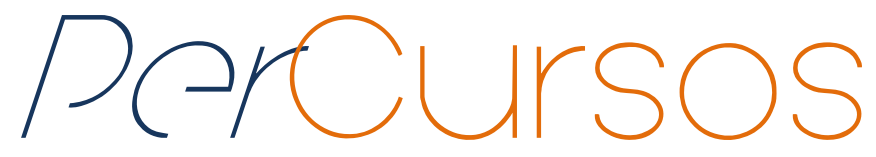

\title{
As relações entre a genialidade e a loucura: um enfoque humanista existencial
}

\section{Resumo}

O presente artigo busca, através de uma revisão bibliográfica não sistemática da literatura, investigar as possíveis relações existentes entre a genialidade e a loucura, o comportamento outsider, a partir da análise de personalidades influentes da história e a visão cinematográfica a respeito do tema proposto. Ainda, o artigo propõese refletir a respeito de questões de ordem psicopatológicas em relação ao diagnóstico, procurando relacionar esses temas com a cinematografia. Acredita-se que o este artigo vem colaborar para a área da psicopatologia em relação às questões de diagnóstico, uma vez que é relevante para a saúde mental pensar no indivíduo para além da classificação de seu quadro, evitando a sua "patologização". Conclui-se que, ao longo da história, a questão do rótulo sempre esteve presente, podendo ser prejudicial ao modo de existência escolhida por cada indivíduo e que a falta de informação sobre o que faz o profissional da saúde mental acaba trazendo desconhecimento do que pode ou deve ser feito para amenizar o sofrimento daqueles que o possuem. É importante diagnosticar para tratar; porém, a abordagem compreensiva mostra-se mais favorável neste sentido, possibilitando a aceitação da liberdade existencial de cada um.

Palavras-chave: Gênios. Doenças mentais. Psicopatologia. Existencialismo. Cinema.

\section{Clarissa de Moraes Guth}

Graduada em Psicologia pelo Centro

Universitário Ritter dos Reis -

UniRitter.

Brasil

clarissapsicologaclinica@hotmail.com

\section{Carlos Alberto Veit}

Doutor Psicólogo pela Pontifícia Universidade Católica do Rio Grande do Sul - PUCRS. Brasil betosul56@ig.com.br

\section{Para citar este artigo:}

GUTH, Clarissa de Moraes; VEIT, Carlos Alberto. As relações entre a genialidade e a loucura: um enfoque humanista existencial. Revista PerCursos, Florianópolis, v. 20, n.44, p. 232 - 257, set./dez. 2019.

DOI: $10.5965 / 1984724620442019232$

http://dx.doi.org/10.5965/1984724620442019232 


\title{
The relations between geniality and madness: An existential humanistic approach
}

\begin{abstract}
The present paper searches through a non-systematic bibliographical review of the literature to investigate the possible relations between geniality and madness, an outsider behavior, based on the analysis of influential personalities of history and the cinematographic vision regarding the proposed theme. Still, this article aims to reflect on psychopathological issues regarding the diagnosis, trying to relate these themes to cinematography. It's believed that this article collaborates in the area of psychopathology in relation to diagnostic issues, since it is relevant for the mental health to think about the individual beyond the classification of their frame, thus avoiding the "pathologization" of the same. It's concluded that, throughout history, the issue of the label has always been present, and it may be detrimental to the mode of existence chosen by each individual and that the lack of information about what the mental health professional does ends up bringing ignorance of what can or should be done to soften the suffering of those who possess it. It is important to diagnose to treat, but the comprehensive approach is more favorable in this sense, making possible the acceptance of the existential freedom of each one.
\end{abstract}

Keywords: Geniuses. Mental illness. Existencialism. Psychopathology. Movie Theater. 


\section{Introdução}

Ao longo dos tempos, desde a antiga Grécia, muitos teóricos, médicos e filósofos dedicaram-se ao estudo da loucura, como a mesma se dava em termos de manifestação ou até mesmo de sua origem (DELATORRE; SANTOS; DIAS, 2011). A partir do que se considera normal ou patológico, procura-se não se limitar apenas às conceituações de ordem médica, como a ausência ou presença de doença ou à psicopatológica, se há adaptabilidade ou funcionalidade ao ambiente ou não, mas se propõe avançar para as questões filosóficas, como as da existência de um indivíduo no mundo (CANGUILHEM, 2009).

As relações que conectam o gênio com o louco sempre suscitaram curiosidade em pesquisadores, filósofos e escritores, pela busca de respostas a respeito de entender como indivíduos que obtiveram corte com a realidade e permanecem mergulhados no mundo de suas fantasias, em sua grande maioria, antes da desrazão, possuíam talento peculiar e quase sempre compartilhavam um comportamento que se desviava do convencionalismo social (WILSON, 1985).

Colin Wilson (1931-2013), quando escreveu sobre o Outsider, definiu-o como sendo um homem fora de lugar devido a sua sensibilidade e ao sentido de justiça que se encontra adormecido pela sua introversão que, porém, lhe mostra por meio do sofrimento o autoconhecimento e o sentido de sua existência, que até o momento que não a define em identidade, se convence de um não pertencimento a sua sociedade. Por isso que, em resumo, um outsider pode ser um artista. Entretanto, nem todo artista é um Outsider, assim como um gênio pode ser um louco, mas nem todo louco é um gênio (WILSON, 1885).

Em meados do século XX, afirmou o psicólogo americano William James (18421910) que, quando se unem intelecto superior a um temperamento desviante, criam-se as melhores condições para o surgimento de um tipo de genialidade que entra para os livros de história. O poeta Edgar Allan Poe (1809-1849) parece compartilhar a mesma ideia com William James, pois em relação à genialidade ele afirmou que, quando um louco parecer completamente lúcido, seria o momento de colocar-Ihe a camisa de força. 
Os filósofos Aristóteles (384-322 a.C.) e Arthur Schopenhauer (1788-1860) também apontaram as semelhanças entre a genialidade e a loucura. Sendo assim, diversos estudiosos ainda questionam a respeito das inúmeras relações que cercam a loucura, sendo uma dessas o pensamento do descrito por Michel Foucault em 1961, mais conhecido como a desrazão (PROVIDELLO; YASUI, 2012).

Com isso, discute-se a respeito da função mental chamada inteligência e sua ligação com a loucura, a partir das manifestações de indivíduos possuidores da genialidade, ou seja, os considerados gênios. As manifestações a partir de pensadores e artistas fazem-nos questionar a respeito do comportamento humano e seu psiquismo.

\section{Metodologia}

O presente artigo é uma revisão bibliográfica não sistemática sobre as possíveis relações existentes entre a genialidade e a loucura, o comportamento outsider e a visão que o cinema passa a respeito do tema. Os filmes citados por esta revisão fazem parte do artigo escrito por Dubugras et al. (2007), que teve como objetivo analisar nove filmes vencedores do Oscar e discutir a respeito das mensagens passadas para o público que assiste sobre o profissional psiquiatra e os pacientes de saúde mental.

Já para o presente artigo, o estudo de Dubugras et al. (2007), propõe-se apenas a colaborar para uma reflexão geral da prática de profissionais da saúde mental em relação ao diagnóstico. Busca fundamentar, como exemplo, a forma como o cinema algumas vezes tende a construir estereótipos de tais diagnósticos e da prática dos profissionais da saúde mental, podendo ser prejudicial aos indivíduos, uma vez que a mensagem passada por um determinado filme acaba direcionando o entendimento de seu público a um determinado ponto de vista, gerando a questão do rótulo.

A revisão bibliográfica apresenta-se como um processo que possui etapas desde a escolha do tema, a sua formulação e elaboração, até a realização da busca em fontes e a própria redação do texto (GIL, 2002). Esse tipo de revisão caracteriza-se por uma pesquisa teórica, pois procura discutir e apresentar conceitos diversos relacionados aos assuntos tratados pelo presente artigo, sendo embasada na literatura anteriormente 
publicada em livros e artigos de periódicos (GIL, 2002). A revisão bibliográfica dos artigos foi realizada através de ferramentas como o Scielo e o Psyclnfo, tendo os seguintes descritores de busca: Gênios, Doenças Mentais, Psicopatologia, Existencialismo e cinema, além da utilização de livros e filmes sobre o tema.

\subsection{O normal e o patológico}

Na história, desde a Antiguidade, por inúmeras vezes tentou-se delimitar o que poderia se considerar normal ou patológico, mas não foi obtido sucesso ao estabelecer critérios para tamanha complexidade (DELATORRE; SANTOS; DIAS, 2011). Logo após, foram criadas várias conceituações do que é normal e patológico, procurando por explicar as supostas origens desses dois estados (DELATORRE; SANTOS; DIAS, 2011).

Um dos autores que tratou desse assunto foi Georges Canguilhem (1904-1995). Ele foi um filósofo e também médico francês que não considerava a existência do normal e do patológico, pois afirmava que tanto a anomalia quanto a mutação são consideradas patológicas, mas mesmo assim ainda são formas possíveis de vida (DELATORRE; SANTOS; DIAS, 2011).

Na concepção do médico e cirurgião René Leriche (1879-1955), citado por Silva et al. (2010), sobre a doença, argumenta que a saúde é a ausência de problemas, ou seja, é o silenciar dos órgãos. Porém, para Canguilhem, isto implica dizer que a doença faz-se existente e somente pode ser prevenida porque antes houve um doente (SILVA et al., 2010). Com isso, Canguilhem traz uma diferenciação muito importante em relação à terminologia desses dois estados, pois ele afirma que o patológico é anormal, mas nem todo o anormal poderia ser chamado de doente, pois, se ele pode adaptar-se ao seu ambiente, não seria classificado como patológico (CANGUILHEM, 1904 apud DELATORRE; SANTOS; DIAS, 2011).

A concepção da perspectiva existencial em psicopatologia, por sua vez, não se utiliza das categorias psicopatológicas e das classificações psiquiátricas como Erthal (1999) citado por Teixeira (2006), nos apresenta, pois elas acabam por fragmentar a totalidade existencial, pelo fato dessa perspectiva aceitar as perturbações mentais como 
sendo apenas um aspecto que se integra à totalidade da existência dos indivíduos (TEIXEIRA, 2006).

Michel Foucault (1926-1984), de forma semelhante, negou-se a criar um novo conceito de loucura em sua obra, pois ele não procurou responder o que era a loucura, mas sim procurou por seu entendimento. Para esse autor, mais valia entender características da loucura e de como a sociedade relacionava-se com ela do que criar outro conceito em psicopatologia, alimentando ainda mais a ordem do que é normal ou patológico e, por conseguinte, a exclusão social (TEIXEIRA, 2006).

Diferenciar o normal do patológico gera constantes discussões conceituais (SILVA et al., 2010), e, em se tratando da própria psicopatologia, essa discussão torna-se mais relevante ainda, pois sua demarcação não é bem clara e as fronteiras que as separam não são muito rígidas (SILVA et al., 2010).

Georges Canguilhem (2009) afirmava a respeito da medicina grega que a natureza do homem, tanto dentro quanto fora dele, precisa estar em harmonia e equilíbrio. Uma perturbação desses fatores é o que causaria a doença. "Nesse caso, a doença não está em alguma parte do homem. Está em todo ele e é toda dele" (CANGUILHEM, 2009, p. 12).

A doença, entretanto, não seria somente um desequilíbrio ou uma desarmonia, mas também o esforço exercido pela natureza sobre o homem para que o mesmo obtenha um novo equilíbrio, podendo a doença ser uma reação generalizada com intenção de curar. É como em uma doença mental que possui alterações das funções mentais e que acaba por produzir um delírio como uma forma de elaborar seus conflitos. Para exemplificar, temos o "caso Schreber" de Freud (1911), em que ele nos descreve a concepção de delírio que estaria articulada à paranoia, mas como uma tentativa de cura do indivíduo (BRIGGS; RINALDI, 2014).

Considerando que há muitas possibilidades fisiológicas e contextuais no processo da vida dos indivíduos, estabelecer uma norma para afirmar a existência de saúde ou de doença apenas acabaria por transformar esses conceitos em um tipo de ideal (SILVA et al., 2010). Ao adentrar no campo da psicopatologia, não é mais possível distinguir o normal 
do patológico, seja pelo desconhecimento da fisiologia dos processos mentais, seja pelo tênue limite entre o que se considera normal ou não (DELATORRE; SANTOS; DIAS, 2011).

Contesta-se o discurso social, aquele que fala da psicopatologia, do que é normal ou anormal e da saúde mental, quando o Manual Diagnóstico e Estatístico de Transtornos Mentais, já em sua quinta edição (DSM-V), considera quase qualquer sofrimento, malestar ou incômodo psíquico como um déficit ou distúrbio e que vem ganhando potencial atualmente (TRAVAGLIA, 2014). Assim, tudo acaba se tornando passível de intervenção do psiquiatra e dos medicamentos.

Todo comportamento e afeto diferente pode ser medicalizado e na compreensão dos tratamentos coloca-se um viés: o da possível correção ou adequação dos comportamentos (TRAVAGLIA, 2014). Isso também não quer dizer que não seja preciso classificar quando necessário, para procurar adequar o melhor tipo de tratamento, quando realmente existe uma patologia ameaçando a funcionalidade do indivíduo.

Por isso, críticas relacionadas à discussão do que seria normal ou anormal, apesar de querer considerar-se a não patologização e a não medicalização dos sujeitos, mas olhar para sua subjetividade, não anulam a importância e a indicação do psicodiagnóstico, principalmente em situações específicas que exigem um estudo mais aprofundado como, por exemplo, em um diagnóstico diferencial (ARAÚJO, 2007). A classificação psicopatológica e a tipificação de comportamentos que são considerados patológicos apenas buscam o entendimento a partir do enquadramento dos indivíduos nos critérios específicos de cada transtorno (HENRIQUES, 2010; TRAVAGLIA, 2014).

O que o artigo se propõe a discutir, em relação ao diagnóstico, parte exatamente do não enquadramento dos indivíduos somente porque se encaixam em critérios, mas procurar por meio de uma abordagem mais humana, que englobe a liberdade existencial de cada pessoa, compreender seu modo específico de vida. A abordagem compreensiva das psicopatologias de Irvim D. Yalom (1980) procura considerar o fator da existência ao promover o entendimento de cada indivíduo de acordo com uma abordagem específica, pois o modo de vida de cada um é subjetivo (HENRIQUES, 2010). 
Ao considerarmos o comportamento outsider ou sua existência em si, é um ponto muito peculiar, pois envolve questões que em algum grau são vistas como patológicas como, por exemplo, o isolamento, sua suposta confusão de identidade e seu traço de introversão (WILSON, 1985).

Somente isso, porém, não fecharia critérios diagnósticos para um quadro de Transtorno de Depressão Maior (TDM), podendo ser confundido com a melancolia, que seria apenas traço. Isso ocorre por ele se sentir sem controle e, não conseguindo agir a seu próprio favor, não aceita o que a sociedade de controle lhe impõe. A disciplina, como já dizia Gilles Deleuse, seria um homem inconformado com o confinamento que a sociedade impõe-lhe (DELEUSE, 1992 apud CORBANEZI, 2012).

Já aspectos citados por Wilson (1985), como o não pertencimento ao social em que vive, por sentir que seus valores não são iguais aos de seu convívio, sua constante apatia e o sentimento de irrealidade que o permeiam, poderiam ser observados dentro de um quadro de Transtorno de Personalidade Esquizóide (TPE). No entanto, o outsider defende uma maneira de ser no mundo e busca pelo autoconhecimento, o que o levaria a defender sua existência por meio de um sentido particular e diferente, mas ainda assim um sentido e não um vazio, como pode ser interpretado pelo TPE.

Dessa maneira, o caminho a ser trilhado a partir do autoconhecimento ou autotranscendência poderia se dar através do altruísmo ou da dedicação, da realização plena do seu potencial ou da criatividade até chegar ao sentido para a existência; caso contrário, dar-se-ia na perturbação, a partir do vazio, do niilismo e das patologias (HENRIQUES, 2010). Assim como acontece anos mais tarde com Nietzsche, o seu descrédito na procura de sentido por outros talvez tenha sido o que colaborou para seu colapso de entrega ao "pensamento do fora" sem ter como voltar.

\subsubsection{A genialidade e a loucura}

Por meio da investigação de questões de ordem psicopatológica, espera-se que se possa tornar possível um olhar para a loucura que seja diferente daquele da classificação diagnóstica (PROVIDELLO; YASUI, 2012). Apesar de ser desafiador, a busca pela relação, investigação e discussão entre genialidade e loucura torna-se importante. 
Alguns autores, como Teixeira Coelho (2002) citado por Providello; Yasui (2012), apontam que nunca poderemos perceber nitidamente qual seria a principal relação entre loucura e a arte (esta última tida como uma manifestação da inteligência). Mas buscar aproximações entre o que as duas compartilham pode nos levar a questões, como que comportamentos, em termos de traços psicológicos, os indivíduos que despertam a loucura desenvolvem e quais as relações diagnósticas são existentes ou possíveis (PROVIDELLO; YASUI, 2012).

A loucura tem o seu próprio criador: o ser humano, pois se não houver um comportamento estipulado, o qual todos os que se relacionam sigam e então apenas um se desvie dele e não haja alguém que o observe para lhe comparar e dizer que não o segue, não há o rótulo. E é exatamente o que, ao longo da obra de Foucault, é relatado. $\mathrm{O}$ autor escreve que a loucura não é um objeto natural, que existe desde o início dos tempos e que fica à espera de ser entendido pelo homem, mas seria criada pelos próprios homens (PROVIDELLO; YASUI, 2012).

Uma das relações entre o artista e o artista louco decorre do chamado "pensamento do fora," conceito criado por Foucault. O "fora" representa o exterior, que por fim seria a desrazão que permeia o pensamento. Esse pensamento do Exterior, ou seja, pensamento que vem do fora, do externo do indivíduo, se comparado com a loucura, compartilha várias peculiaridades: ambos se parecem; todavia, o pensar por fora das situações não é considerado a loucura em si (PROVIDELLO; YASUI, 2012).

O artista compartilha deste mesmo "fora de pensamento" que é o louco. Porém, não podemos considerá-lo louco, pois, quando mergulha no pensamento do fora, não se entrega totalmente e volta. Já o louco afunda-se no pensamento do fora e não volta mais. O fora e a arte são de domínio dessa desrazão, que seria uma não razão ou fora dela. É como no ditado que diz: "o louco se afoga no mar em que o poeta nada" (PROVIDELLO; YASUI, 2012, p. 1523). A loucura é retratada como sem volta, pois se entrega totalmente ao pensamento do fora. Já o artista, por buscar inspiração para sua arte, mantém com este tipo de pensamento uma relação de ida e volta (PROVIDELLO; YASUI, 2012). 
Assim também faz um gênio, pois sua função mental inteligência precisa pensar as situações por fora e é com este "pensamento do fora", descrito por Foucault, que ele pode buscar as respostas para o mais complexo dos problemas ou para sua criação. A maneira com que os dois se relacionam com o fora se diferencia: enquanto um gênio e um artista vão e voltam de seu pensamento, para adquirir inspiração, um louco entregase totalmente ao lado do fora, como em um colapso e não consegue retornar (PROVIDELLO; YASUI, 2012).

Em se tratando de relações existentes entre genialidade e loucura, apresenta-se uma visão antiga e romanceada de filmes e também da literatura: a do gênio romanceado ou uma visão fantasiosa do gênio. Ele é o gênio que o cinema e a literatura ajudaram a criar estereótipos e este, por sua vez, é tido como inspirado e ultrassensível. Possuindo suas estranhas manias, seria isolado representando sua solidão constante e também um visionário dotado de inteligência e de ideias grandiosas, as quais ninguém pensou ou sonhou que pudessem dar certo. Esse gênio, o romântico, acabaria com certa frequência associado à loucura (DOS ANJOS, 2014).

No contexto da monarquia e do liberalismo na França, questionava-se o estético profundo e o ir além da adequação política na época. Tanto o imaginário quanto os temas da época giravam no entorno da questão da loucura, pois acreditavam que poderia se dizer muito através das perspectivas românticas como: a antinormatividade, a criatividade, a inteligência, reportando-se à figura dos gênios e, por fim, à liberdade (DOS ANJOS, 2014). É nesse debate que muito foi produzido em torno da genialidade e da função da arte, com suas manifestações sobre o tema da loucura no pensamento romântico.

Na literatura, segundo Dos Anjos (2014, p. 6), o louco torna-se o próprio gênio criador e é através de sua criatividade que coloca luz na criação. "William Shakespeare, Victor Hugo e Dante, são exemplos de escritores do pensamento romântico na literatura que evocavam em suas obras a ligação entre genialidade e loucura: Como é filósofo esse visionário! Como é sabido esse louco!". 
Então se remete à questão do gênio ser o símbolo da humanidade. Apesar do mesmo possuir muitos pontos de interconexão com o louco, não poderia ser atrelado totalmente à desrazão e ao isolamento pelo simples fato de pensar por regras não estabelecidas convencionalmente. Cabe colocar que o pensamento exterior e o não convencional são compartilhados pelos dois; porém, sua manifestação no gênio, através da criatividade e da inteligência, é de forma bem peculiar, pois ainda há o controle essencial do pensar racional.

A metáfora e a máscara que o signo da não razão coloca sobre a face do louco e que tenta aplicar também à figura do gênio configura-se apenas em um de seus traços, mas não o explica por completo (DOS ANJOS, 2014). Dessa maneira, a condição rara e especial que se reporta ao gênio pressupõe que a sua loucura esteja apenas relacionada com a questão de ser um alguém de exceção. A loucura então seria "genérica" e de liberdade (DOS ANJOS, 2014). A loucura do gênio partiria da consciência e de uma insensatez tranquila. Não seria uma loucura qualquer, mas uma loucura genial tornandose libertadora.

\subsubsection{O comportamento outsider}

O primeiro autor a falar sobre o outsider foi Colin Henry Wilson (1931-2013), um escritor inglês do gênero da ficção e da não ficção que se popularizou por meio da filosofia chamada existencialismo fenomenológico ou novo existencialismo. O autor escreveu seu livro -“O Outsider: O drama moderno da alienação e da criação,"- publicado em 1956, quando tinha apenas 24 anos de idade. Em seu livro, Wilson trata de um estudo original sobre a alienação, a criatividade e a mentalidade moderna do espírito humano (WILSON, 1985).

“À primeira vista, o outsider é um problema social. É um homem fora de lugar" (WILSON, 1985, p.1). Isso pode nos levar a pensar que esse tipo de sujeito não passa de um neurótico, por intermédio de algum instinto profundo ou um solitário (WILSON, 1985). O outsider parece fazer uma acusação à sociedade porque todos nós possuímos instintos selvagens, impulsos perigosos e inomináveis, mas muitos mantêm as aparências da normalidade para si mesmos e para os outros; porém, um outsider defende a verdade 
e não a aparência. No entanto, apesar de ser uma forte acusação ao social, ela acaba por enfraquecer-se pelo fato da evidente "anormalidade" e introversão (WILSON, 1985).

O outsider é alguém que despertou para o caos, ou seja, o caos é então a verdade que ele defende. Ele não pode viver em um mundo protegido e confortável da sociedade, aceitando como realidade tudo o que vê e toca, pois o que vê é o caos; é a verdade (WILSON, 1985). Um outsider enxerga mais profundamente e ele pode ter talento e sensibilidade, assim como esses aspectos podem não estar presentes, uma vez que há uma grande tentação em identificá-lo com o artista e acabar por transformar algo complexo, como a normalidade e o patológico visto anteriormente, em simplista.

Para demonstrar o quanto o comportamento do outsider é complexo, Colin Henry Wilson destaca:

Sendo assim, um Outsider pode ser um artista, mas o artista não é, necessariamente, um Outsider. Afinal, muitos artistas não compartilhavam nenhuma das características do Outsider, dentre os quais podemos citar Shakespeare, Dante, Keats, pois eram socialmente bem ajustados (WILSON, 1985, p. 5).

Aparentemente o que caracteriza um outsider é a sensação de estranheza e de irrealidade, porque para ele o mundo não é racional e nem ordenado, por isso pensa que a verdade deve ser dita, custe o que custar, senão não haverá esperança em uma restauração da ordem desse caos eminente (WILSON, 1985). Para Wilson (1985, p. 8), “A atitude básica característica de um Outsider é a não aceitação da vida, essa vida humana vivida por seres humanos numa sociedade humana". Na verdade a alegação é a de ser o único que se sabe doente em uma sociedade que não se reconhece doente, bem como diz o dito popular: "Em terra de cego, quem tem um olho é rei” (WILSON, 1985).

O reinado que parece querer proteger é o que reina sobre o nada, pois não lhe são concedidos direitos e nem poderes. Nesse reinado, o outsider parece viver no vazio. Ele perde sua fé e não vê sentido para ser ele mesmo, por isso sua força de agir esgota-se e ele conclui que o mundo não possui valores. Ele se enxerga diferente e como não 
pertencendo ao mundo em que vive. Não quer se inserir nele, pois os seus valores não são iguais aos desse mundo. Ele se percebe perdido.

O outsider é o que enfrenta o fato desagradável de que a sociedade está doente, bem como o pensamento do filósofo dinamarquês do existencialismo Kierkegaard do, no século XIX: "Se me puserem em um Sistema, me negam - não sou um mero símbolo matemático - eu sou." A pergunta que ele parece a todo instante querer responder e que somente conseguiria a partir do autoconhecimento é a de saber por que a sociedade procura enquadrar-se; por que ela possui um início, um meio e um fim, com a necessidade de que todos os que vivem nela passem pelas mesmas situações ou façam tudo igual.

Quando se fala em existencialismo, pensa-se na filosofia do outsider, pois tanto Kierkegaard quanto Nietzsche tinham orgulho de se declarem como outsiders. Eles desenvolveram uma filosofia a partir do outsider em suas obras e mais tarde Sartre e Camus deram continuidade a essa ênfase (WILSON, 1985), que seria a de que todo o homem possui um determinado modo de existência e que por isso não poderia deixá-la à deriva, sem que por meio dela não colhesse nem um fruto. A natureza humana é possuidora de liberdade suficiente para transformar todo homem em capaz de fazer algo enquanto existir. É como dizia Nietzsche, todo homem é um gênio.

Por isso, podemos dizer que existencialismo é uma expressão de Kierkegaard que pode ser usada atualmente para falar da filosofia dos outsiders (WILSON, 1985), pois todo o sentido existencial que é abordado nessa filosofia tende a discutir o existir e o como existir no mundo, o que pode se tornar um aspecto do sentimento de não pertencer ao convencional que faz parte do comportamento outsider.

Os filósofos citados aproximam-se em pensamento, pois buscam a interioridade dos seres e o desenvolvimento da individualidade. Na sociedade, os homens vivem sendo reféns do que é falado; não se reconhecem como indivíduos com escolhas próprias, ou seja, não são autênticos, pois parecem seguir as vontades da sociedade. A mais importante das tarefas do existir no mundo seria um comprometimento profundo com a interioridade (FARIAS, 2011). 
Assim como abordado anteriormente em o normal e o patológico, a perspectiva existencial em psicopatologia enxerga as deficiências, perturbações e debilidades humanas como um modo de existência no mundo. Sendo assim, as perturbações mentais seriam apenas um conjunto de formas de expressão parciais e dos modos de construir o seu próprio mundo; portanto, aceita-se como sendo uma possibilidade humana universal poder escolher um modo de existir no mundo (TEIXEIRA, 2006).

Também é possível situar o comportamento do outsider como sendo a sua própria escolha de existir no mundo. Porém, é diferente esse existir no mundo, podendo para alguns tornar-se opaco por seu modo frustrado de encará-lo, como afirma Teixeira:

Acaba por ser uma forma de existência frustrada na qual o indivíduo se fecha a si mesmo, tornando-se opaco para si próprio e perdendo a comunalidade com o mundo do outro. Frankl $(1986,1984)$ e Maddi (1970), cada um pelo seu lado, enfatizaram que a procura do sentido seria a motivação fundamental do indivíduo e que a psicopatologia estaria associada à falta de sentido para a vida que, deste modo, teria o estatuto de frustração existencial. (TEIXEIRA, 2006, p. 406).

O outsider poderia estar associado com a melancolia, pois acredita que o caos que enxerga de fora é uma verdade. Mas, mesmo sendo verdade, atribui seu mundo como sendo sem valor. Apesar desse comportamento, modo de pensar e da maneira como se coloca e se enxerga no mundo, o outsider possui um sentido em seu viver, que seria o de defender a verdade e não as aparências. Esse sentido engloba-se em torno tanto do seu realismo, sendo outsider realista, quanto em torno da visão romântica, como um outsider romântico (WILSON, 1985). Por isso cabe dizer que há por essência uma renúncia da vida, mas porque não se encaixa nos valores postos por ela.

Porém, ao mesmo tempo, há uma constante busca por saber viver melhor, não viver comumente, mas viver para resolver ou solucionar seus próprios problemas de existência. Assim como afirma Wilson (1985, p. 61): “O homem que se interessa em saber como deveria viver em vez de simplesmente aceitar a vida tal como ela é, torna-se automaticamente um outsider". Desse modo, seu comportamento parece possuir um 
viés, pois tanto pode ser classificado como patológico quanto como normal. Sua fronteira é tênue como a de qualquer comportamento, pois o outsider aceita viver, o que ele parece não aceitar são os valores desse viver. Por isso, não é fácil sua descrição já que ele não é mero raciocínio, mas um tipo de existência. E sua primeira tarefa é buscar pelo autoconhecimento (WILSON, 1985).

Ser um outsider também é adentrar as questões da identidade, pois, como coloca Wilson (1985, p. 145), um “Outsider não tem certeza de quem ele é. Ele encontrou um 'Eu', mas este não é o seu verdadeiro 'eu.' Sua verdadeira preocupação é o de encontrar o caminho de volta a si mesmo". Sendo assim, pode-se concluir que o outsider é também um visionário, pois enxerga sempre à frente de seu tempo e suas ideias são na maioria das vezes extravagantes e grandiosas.

\subsubsection{Os grandes nomes da história}

“O impossível é sempre mais sedutor que o possível."

(Jean Paul Sartre)

Como os outsiders defendem a verdade, porém, enfraquecem-se ao mantê-la, parecem defender uma única distinção que consideram por vez importante, que seria entre o ser e o nada. Um outsider tem por expressão o existir e não as distinções como corpo e espírito, homem e natureza, pois essas o levariam a pensar pela teologia e a filosofia, o que ele parece rejeitar (WILSON, 1985).

O seu pensamento é próprio, lembrando que não se sente pertencente ao mundo em que vive, somente ao nada, podendo criar sua própria filosofia de vida. Isso aparece no comportamento de alguns artistas. Porém, lembrando que não há generalização e disso, até a genialidade e a loucura compartilham também. Segundo Sales:

Aristóteles (384-322 a.C.) afirma que um gênio manifesta-se na doutrina da capacidade inventiva, não necessariamente "louca" ou irracional do criador da arte, seja qual arte for. Quanto a Kant (1980), o gênio possui duas características básicas ressaltantes, são elas: o talento e a disposição natural para criar. (SALES, 2006, p. 142). 
A partir disso, podemos observar que grandes nomes marcaram a história por possuírem tais características citadas, tornando suas obras memoráveis, tanto na arte, quanto na filosofia ou nas ciências. Segundo os autores Bueno e Arana:

Um deles foi Vincent Van Gogh (1853-1890), pintor holandês, que criou uma nova maneira de entender o mundo e influenciou inúmeros artistas, foi detentor de um modo de expressar paixões e sentimentos que brotavam de sua mente doentia e de sua alma atormentada. (BUENO; ARANA, 2015, p. 1682).

Apesar de ser portador de uma enfermidade mental, não quer dizer que todos os gênios e outsiders terão ligações diretas com alguma doença, como Vincent Van Gogh teve. Superdotados e indivíduos com algum transtorno manifestado terão necessariamente comportamento outsider, lembrando que um outsider pode ser um artista; porém, nem todo artista é um outsider (WILSON, 1985).

Vincent Van Gogh viveu grande parte de sua vida sofrendo de crises de depressão nervosa e passando por períodos de enfermidade mental, o que lhe rendeu um grande histórico de internações em instituições psiquiátricas e, ao longo da vida, muitas turbulências pessoais (BUENO; ARANA, 2015). Seu temperamento instável fazia com que não conseguisse encarar a vida com a despreocupação, pois as mágoas e desilusões que obteve ao longo dela sempre feriam-no profundamente, se comparado às outras pessoas, e em seu comportamento eram bem visíveis as suas excentricidades (WILSON, 1985).

A sensibilidade e o enxergar profundo, o viver durante muito tempo sem rumo, a incapacidade de se conectar com a fé e considerar a condição de descrença como consequência de uma queda são características que fazem de Vincent Van Gogh um outsider. Conforme coloca Wilson (1985, p. 84), sobre Van Gogh, a vida para ele pareceu não passar de "uma questão crítica e dolorosa que precisava se resolver antes de ele começar a viver". Por isso, sua vida foi uma intensa luta entre os desacordos com o universo, pelos quais todo artista passa, enxergando uma finalidade em sua vida para 
tudo, inclusive para as suas desgraças e o resto do tempo tentando reconquistar este insight através da disciplina, que seria sua arte (WILSON, 1985).

Outro grande nome lembrado na história foi o filósofo Friedrich Nietzsche (18441900). Ele também compartilha do comportamento outsider como o pintor anteriormente citado. Nietzsche toma para si termos como criação e arte para gerar, a partir de seus atos que parecem não se esvair, um novo processo constante de vida. Nessa passagem, podemos notar a sensibilidade e a genialidade de Nietzsche ao tratar da existência. Sendo assim, para ele a arte seria a essência criadora e de potencialidade (COSTA, 2016).

Ele era religioso e pertencia à tradição romântica que acreditava que todo homem é potencialmente um herói e um gênio; que só a inércia faz o homem medíocre. Além disso, Nietzsche, em grande parte de seu tempo em vida, encontrava-se constantemente em sua introspecção profunda em meio aos livros ou em caminhos solitários. Como um gênio romântico, Nietzsche aceitou sua condição solitária e durante sua vida foi convencido dessa condição, após ler um de seus autores favoritos: Shopenhauer (Wilson, 1985). Em suas obras, pode-se observar a questão da busca pelo autoconhecimento e também pela existência da verdade, características do comportamento Outsider.

Outro filósofo conhecido que também faz parte do tema proposto é Soren Kierkegaard (1813-1855). Assim como Nietzsche e Van Gogh, esse filósofo apresentava aspectos diferenciados em seu comportamento. Apesar disso, há quem diga que a loucura não era o aspecto que lhe ressaltava em termos de constituição psíquica (STRATHERN, 1999). Assim como Nietzsche, ele era um solitário, mas possuidor de uma estranha habilidade de imaginação e vestia-se e comportava-se de forma antiquada e era motivo de estranhamento, mas notável sua inteligência (STRATHERN, 1999). Nisso podese observar aspectos do comportamento outsider, como o não enquadramento ao convencionalismo social e o aspecto visionário.

O último nome de destaque na história é no campo da ciência: Isaac Newton (16431727). Ele apresentava alguns aspectos do comportamento de um outsider, pois, além de pensar à frente de seu tempo, seu comportamento sempre foi bem diferente. Newton foi considerado pela maioria de seu convívio como um garoto sozinho, silencioso e 
pensativo, dando indícios de sua diferença entre os outros, não somente pelas habilidades mecânicas, mas pelo isolamento e aversão a outras crianças (PONTONE, 2001). Assim, todos esses exemplos citados parecem compartilhar dos três aspectos abordados neste artigo: genialidade, loucura e o comportamento outsider.

\subsubsection{Sob o olhar cinematográfico}

De acordo com o interessante estudo feito por Dubugras et al. (2007), a cinematografia traz diversos olhares sobre a doença mental e o papel profissional do psiquiatra, mas isso pode estender-se também aos psicólogos e demais agentes da saúde mental. Em seu artigo sobre a estigmatização da atuação dos psiquiatras, foram estudados nove filmes vencedores de prêmios da Academia de Artes e Ciências Cinematográficas (Oscar), entre os anos de 1991 e 2001, sendo eles os seguintes: O silêncio dos inocentes, As Loucuras do Rei George, Gênio Indomável, Garota Interrompida, Shakespeare Apaixonado, Melhor é Impossível, Shine - Brilhante, Mente Brilhante e Céu Azul.

A análise feita por eles desses filmes foi a partir da caracterização dramática de 17 personagens, sendo possível identificar associações entre o profissional psiquiatra e os temas principais dessas produções, tais como: a genialidade, a doença mental, a interdição, a postura profissional e o processo de recuperação dos pacientes. O objetivo do estudo era determinar se os enredos dos filmes citados passaram mensagens negativas ou idealizadas a respeito do profissional. Nisso, Dubugras et al. apresentam-nos como conclusão da pesquisa que:

Os filmes estudados não contestam a validade da psiquiatria, mas apresentam uma batalha entre a abordagem tradicional e uma não tradicional, advogando que um psiquiatra deve ser alguém fora dos padrões e excepcionalmente talentoso para ser capaz de entender e tratar uma pessoa. As críticas e as imagens negativas apresentadas nessas tramas podem ser um reflexo do profundo estigma existente na sociedade em relação aos profissionais de saúde mental e pacientes. (DUBUGRAS ET AL., 2007, p. 100). 
Nesse sentido, se a psiquiatria não existisse, o cinema a criaria de alguma forma, pois ele acaba por passar uma imagem às vezes negativa, fantasiosa e idealizada do profissional, dos comportamentos e da própria doença mental (DUBUGRAS et al., 2007). Ainda podemos dizer que há falta de informação à população a respeito do que faz realmente cada um dos profissionais que trabalha com a saúde mental e também sobre as enfermidades de que eles tratam.

Autores citados por Dubugras et al. (2007), como Philo (1994) e Metz (1968), afirmam que a população acaba sendo influenciada por informações da mídia, muito mais do que pelo contato na realidade com pacientes e isso acaba por fazer com que a sociedade faça interpretações e leituras de acordo com as convenções cinematográficas. Portanto, pode-se concluir que os personagens da trama e os elementos do enredo transmitem mensagens sobre os profissionais da saúde mental e de seus pacientes de forma errônea.

O estudo de Dubugras et al., em sua discussão, apresenta várias associações com o tema pesquisado, fazendo alusão ao psiquiatra e doentio Dr. Hannibal Lecter de "O silêncio dos inocentes", como sendo um ser excepcional por sua genialidade, mas louco por seus atos violentos. De acordo com o estudo, isso levaria a uma rotulação do profissional e, em relação à população que assiste, causaria dúvidas que não são sanadas, como as seguintes:

Sua capacidade de analisar os conflitos humanos se deve a sua formação de psiquiatria ou a sua condição de louco? É o Dr. Lecter ou o doente Hannibal quem consegue controlar a mente e a vontade das outras pessoas? Sua genialidade está associada a sua insanidade? Os traços contraditórios e superlativos do personagem podem conduzir os espectadores a relacionar habilidades profissionais com uma mente doentia. "O silêncio dos inocentes" associa psiquiatria e loucura, psiquiatria e manipulação, brilhantismo e loucura, a capacidade de entender a mente humana e um poder sobrenatural, análise e canibalismo, doença mental e violência. (DUBUGRAS ET AL., 2007, p. 106). 
Com isso, o artigo de Dubugras et al. (2007) tem muito a contribuir, como forma de exemplo, para o tema do presente artigo, pois mostra, por meio das tramas de tais filmes descritos, toda a construção de conceitos trazidos pela mídia como forma de criar estereótipos e rótulos aos membros da sociedade, que muitas vezes só terão esse meio de contato com o ponto em questão, seja ela o cinema sejam outros meios de comunicação e de arte. E, com isso, também o conceito de genialidade atribuído ao nome de superdotação ou altas habilidades acaba por sofrer, muitas vezes, com as falsas imagens passadas pela mídia. Idealizações essas que, por sua vez, irão rotular negativamente os indivíduos que dela compartilham.

É importante destacar, em termos diagnósticos, que a definição para um gênio ou superdotado engloba os comportamentos e traços estando acima da média da população, quando observados e comparados, além de se considerar a questão da permanência e duração desses comportamentos (RECH; FREITAS, 2005). Isso parece comprovar a falta de informação correta e séria à sociedade, pois observamos que grandes nomes da história tinham essa característica peculiar, sendo considerados diferentes por aqueles de seu convívio.

Por isso, a identificação de pessoas com altas habilidades não é um processo simples. É algo que requer uma avaliação cuidadosa e feita em equipe interdisciplinar, pois não é aceitável uma mensuração definitiva dos indivíduos e de sua inteligência, até porque altas habilidades variam em cada caso (RECH; FREITAS, 2005). E isso também se faz presente quando se adentra no campo de qualquer enfermidade mental ou comportamento em que se discute o que pode ser normal ou patológico.

O filme Natureza Selvagem, para citar outro exemplo, de 2007, do diretor Sean Penn, é uma adaptação do livro do autor Jon Krakauer, de 1996, que narra a biografia de Christopher McCandless e suas viagens através da América do Norte até sua vida no deserto do Alaska, no início da década de 1990. No filme é retratada a história do rapaz que desafia o modo de vida convencional da sociedade em busca de viver um dia de cada vez. Ele desfruta da liberdade de poder ser quem realmente ele quer ser. 
Ao longo de sua trajetória, ele foi um brilhante aluno de sua classe, um ótimo atleta; porém, sempre demonstrou ser mais maduro do que os outros rapazes de sua idade. Ele também contestava muito o materialismo e a necessidade de seguir uma vida igual à de todo mundo. Com isso, gerava muitos conflitos com sua família, pois seus planos não eram os mesmos que seus pais esperavam para ele. Isso já mostra o desejo de não pertencer ao seu mundo, de romper com a conformidade que the era imposta. A partir da viagem rumo ao deserto do Alaska, McCandless faz muitas amizades intensas, mas acaba cortando os contatos com o mundo.

Há discussões em torno do diagnóstico de McCandless. Há quem diga que se enquadrava nos critérios do Transtorno de Personalidade Esquizóide (TPE). Porém, se observarmos bem, o rapaz possuidor de espírito livre encaixa-se melhor com o comportamento outsider. Assim, tendo como exemplo o artigo de Dubugras et al (2007) a respeito da análise de nove filmes, pode-se concluir que os profissionais que convivem de perto com a área da saúde mental possuem uma importante função em nossa sociedade, que seria a de informá-la e instruí-la a respeito do seu próprio trabalho e também de colaborar para a desconstrução de conceitos e estereótipos, que na maioria das vezes são retratados nos filmes, levando o diagnóstico que deveria ser uma ferramenta ou um processo que procura beneficiar os indivíduos, continuar sendo visto pela sociedade como algo ameaçador.

\section{Discussão}

Na área da saúde, da qual a Psicologia também faz parte, não se afirma e nem se descarta nenhuma possibilidade em relação a diagnosticar, pois existem múltiplos fatores que podem colaborar para um diagnóstico (CANGUILHEM, 2009). Há mais critérios de normalidade do que o simples constatar da doença ou adaptabilidade (DELATORRE; SANTOS; DIAS, 2011). Acredita-se não ser necessário classificar um indivíduo sem antes pensar nas possibilidades de sua existência e sem se considerar a linha e o processo de um tratamento adequado em seu percurso (COUTINHO, 2007). 
Há muitas relações entre a genialidade e a loucura, sendo o "pensamento do fora", descrito por Michel Foucault, e o comportamento Outsider em termos psicológicos e existenciais, descritos por Colin Wilson, apresentado no artigo, apenas duas entre elas. Considerar o fato de um indivíduo ser movido por seu sofrimento, tristeza ou melancolia em depressão ou classificar um sujeito pelo seu desvio social como sendo um transtorno de personalidade, apenas pela escolha de seu modo de vida, não é olhar para sua constituição que é complexa; seria como não aceitar de fato o potencial da sua existência.

Não aceitar as diferenças ou os valores, os quais em nossa sociedade produzem-se e se reproduzem durante os tempos, junto de suas mudanças constantes, não é exatamente negar a existência ou simplesmente não dar sentido para ela, mas sim fazer uma única opção: a de ser livre, a de escolher viver pelo tipo de valores em que se acredita. E isso, traduzido em liberdade, não deveria ser julgado, analisado ou enquadrado (COUTINHO, 2007).

Os profissionais da saúde mental, em particular os psicólogos, sabem que o cerne de um tratamento de sucesso é respeitar as opções dos indivíduos, ajudá-los a amadurecer, proporcionando o autoconhecimento, promovendo a elaboração de possíveis conflitos internos, ou seja, proporcionar liberdade (TEIXEIRA, 2006; ARAÚJO, 2007; TRAVAGLIA, 2014).

Em 1790, Kant deixou claro ao afirmar que o próprio artista não sabe dizer sobre sua criação (SÜSSEKIND, 2009). Com isso, podemos associar o artista ao outsider. Mas, mesmo possuindo esse traço ou característica em comum, não nos permite afirmar que todo artista de fato é outsider. Um outsider pode apenas dizer ou rejeitar aquilo a que não quer se enquadrar; porém, falta-lhe coragem sobre o que fazer para mudar o caos que enxerga.

Não podemos associar também ao gênio e sua condição de alguém de exceção sem considerar que o mesmo sabe muito bem explicar por meio de sua inteligência complexa sua invenção ou teoria. Isso tudo por si só já nos mostra o quanto são complexas as facetas de nosso comportamento e nossa constituição psíquica para podermos enquadrá-la apenas em critérios. 
Há que se considerar um trabalho árduo e profundo de cada caso, pois as mesmas condições e aspectos citados, nos permitem refletir sobre a existência de cada um que, ao se considerar complexa, pode se apresentar de diferentes formas em cada um de nós.

\section{Considerações finais}

Se considerarmos o fato das questões existenciais serem complexas, isso não nos possibilitaria olhar para elas em busca de uma melhor compreensão. É preciso pensar para além dos critérios que possam apenas julgar os indivíduos impossibilitando-os de desfrutarem de suas vidas (COUTINHO, 2007). É sabido que para traçar um plano de tratamento é preciso, antes de tudo, um profissional consciente do poder que possui, mas não uma conscientização que parte da idealização errônea vinda de filmes (DUBUGRAS et al., 2007). Quando seguimos essa linha lógica de pensamento, podemos não perceber que a imagem do psicólogo ou de quem trata a saúde mental venha a se transformar numa fantasia do que se pode ou se deve fazer para ajudar quem sofre.

Não é apenas a maneira com que fazemos um diagnóstico ou o que utilizamos para esse fim que pode ser uma das maneiras de desmitificar o que o cinema com seus filmes reproduzem na sociedade. É preciso pensar em estratégias e intervenções eficientes que englobem como informar a população do que faz cada um dos profissionais da saúde mental. Já os profissionais da saúde mental precisam constantemente rever suas atuações e buscar mais atualização e conhecimento, podendo refletir suas atuações quando em prática.

É sempre possível buscar pelo entendimento e a compreensão dos indivíduos. Antes de enquadrá-los em categorias com o uso de testes e de outras ferramentas, o ser humano encontra-se em processo de constantes mudanças. Sendo assim, o que ele é hoje poder vir a não ser mais amanhã, mas o poder de um rótulo que foi lhe dado pode vir a permanecer tencionando o indivíduo que foi classificado e moldando suas escolhas e futuro. 


\section{Referências}

ARAUJO, Maria de Fátima. Estratégias de diagnóstico e avaliação psicológica. Psicol. teor. prat., São Paulo, v.9,(- n.2-), p.126-141, dez. 2007. Disponível em:

$<$ http://pepsic.bvsalud.org/scielo.php?script=sci_arttext\&pid=S151636872007000200008\&lng=pt\&nrm=iso>. acessos em 10 fev. 2020.

BUENO, T. C.; ARANA, A. R. A. As formas de loucura na arte: um estudo sobre Vincent Van Gogh. ColloquiumHumanarum, Presidente Prudente, v. 12, 1680-1688, 2015. Edição especial.

BRIGGS, Raquel; RINALDI, Doris. O sujeito psicótico e a função do delírio. Rev. latinoam. psicopatol. fundam., São Paulo, v. 17, n. 3, p. 416-430, Sept. 2014 . Available from <http://www.scielo.br/scielo.php?script=sci_arttext\&pid=S141547142014000300416\&lng=en\&nrm=iso >. access on 10 Feb. 2020. http://dx.doi.org/10.1590/1415-4714.2014v17n3p416-3.

CANGUILHEM, G. O normal e o patológico. Rio de Janeiro: Forense Universitária, 2009.p.12-44.

MEYER, Luiz. Melancolia de Lars Von Trier e a psicopatologia contemporânea. J. psicanal., São Paulo, v. 46, n. 84, p. 239-251, jun. 2013. Disponível em <http://pepsic.bvsalud.org/scielo.php?script=sci_arttext\&pid=S010358352013000100021\&lng=pt\&nrm=iso>. acessos em 10 fev. 2020.

COUTINHO, Alberto Henrique Soares de Azeredo. Escutar é preciso, diagnosticar não é preciso. Reverso, Belo Horizonte, v. 29, n. 54, p. 99-108, set. 2007 . Disponível em <http://pepsic.bvsalud.org/scielo.php?script=sci_arttext\&pid=S0102$73952007000100015 \&$ Ing=pt\&nrm=iso>. acessos em 10 fev. 2020.

COSTA, G. B. N. Nietzsche, vida como obra de arte. Rev. Lampejo, Civilização Brasileira, Rio de Janeiro, (v.1), p. 119-122, 2016.

Delatorre, M., dos Santos, A., \& Dias, H. (2013). O NORMAL E O PATOLÓGICO: Implicações e Desdobramentos no Desenvolvimento Infantil. Revista Contexto \& Saúde, 11(20), 317326. https://doi.org/10.21527/2176-7114.2011.20.317-326

DOS ANJOS, Y. C. Sem regra nem-loucura e criação na discussão romântica em torno do gênio. Revista Criação \& Crítica, São Paulo, V.6, n (-13-), p. 3-11, 2014.

DUBUGRAS, M. T. B et al. A imagem do psiquiatra em filmes ganhadores do Prêmio da Academia entre 1991 e 2001. Rev. Psiquiatria, Rio Grande do Sul, v. 29 (-n. 1-), p. 100-109, 2007. 
FARIAS, Í. S. Nietzsche e kierkegaard: os críticos da decadência da sociedade ocidental.

Pensando- Revista de Filosofia, Teresina - Piauí, V.2, (-n.4-), 2011.

GIL, A. C. Como elaborar projetos de pesquisa. São Paulo: Atlas, 2002.

HENRIQUES, Gabriel. O isolamento existencial e a psicopatologia. Análise Psicológica, v. 28, n.4, p. 631-642, 2010. Disponível em: http://www.scielo.mec.pt/scielo .php?script=sci_arttext\&pid=S0870-82312010000400006\&lng=pt\&tlng=pt. Acesso em: 29 set.2017.

PONTONE JUNIOR, Renato. A vida de Isaac Newton. Rev. Bras. Ensino Fís., São Paulo, v. 23, n. 2, p. 256-258, June 2001. Available from <http://www.scielo.br/scielo.php?script=sci_arttext\&pid=S1806$11172001000200018 \&$ Ing=en\&nrm=iso $>$. access on 10 Feb. 2020. http://dx.doi.org/10.1590/S1806-11172001000200018.

PROVIDELLO, Guilherme Gonzaga Duarte; YASUI, Silvio. A loucura em Foucault: arte e loucura, loucura e desrazão. Hist. cienc. saude-Manguinhos, Rio de Janeiro, v. 20, n. 4, p. 1515-1529, Dec. 2013. Available from <http://www.scielo.br/scielo.php?script=sci_arttext\&pid=S010459702013000401515\&lng=en\&nrm=iso $>$. access on 10 Feb. 2020. http://dx.doi.org/10.1590/S0104-59702013000500005.

RECH, A.J.D.; FREITAS, S.N. Uma análise dos mitos que envolvem os alunos com altas habilidades: a realidade de uma escola de Santa Maria/RS. Revista Brasileira de Educação Especial, Marília, v. 11, n. 2, p. 295-314, 2005.

SALES, E. O conceito de gênio na filosofia. Cadernos de arquitetura e urbanismo, Paraná, (-n.2-), 2006.

SILVA, T. L. G. et al. O normal e o patológico: contribuições para a discussão sobre o estudo da psicopatologia. Aletheia, Canoas, n. 32, p. 195-197, 2010. Acesso em: 15 set.2017.

STRATHERN, P. Kierkegaard em 90 minutos. Rio de Janeiro: Jorge Zahar, 1999.

SÜSSEKIND, P. Considerações sobre a teoria filosófica do gênio. Cadernos de EstéticaAplicada, v. 8, (-n. 7-), p. 27-37, 2010.

TEIXEIRA, J. A. C. Problemas psicopatológicos contemporâneos: Uma perspectiva existencial. Análise Psicológica, v. 24, (-n. 3-), p. 405-413, 2006. Disponível em: http://www.scielo.mec.pt/scielo.php. Acesso em: 15 set.2017. 
TRAVAGLIA, A. A. S. Psicanálise e saúde mental, uma visão crítica sobre psicopatologia contemporânea e a questão dos diagnósticos. Psic. Rev., São Paulo, v. 23, (- n. 1-), p. 31-49, 2014.

WILSON, C. O outsider: o drama moderno da alienação e da criação. São Paulo: Martins Fontes, 1985.

Recebido em: 03/05/2018 Aprovado em: 10/10/2018

Universidade do Estado de Santa Catarina - UDESC Centro de Ciências Humanas e da Educação - FAED Revista PerCursos Volume 20 - Número 44 - Ano 2019 revistapercursos@gmail.com 